\title{
STUDI EKOLOGI DAN PEMANFAATAN TUMBUHAN FAMILI SOLANACEAE DI KECAMATAN TUGUMULYO
}

\section{Study of Ecology and Utilization of Family Solanaceae in Sub- District of Tugumulyo}

\author{
Yuli Febrianti ${ }^{1}$, Yuni Krisnawati ${ }^{1}$ \\ ${ }^{1}$ Program Studi Pendidikan Biologi, Jurusan Pendidikan Matematika dan Ilmu \\ Pengetahuan Alam, STKIP-PGRI Lubuklinggau, Sumatera Selatan, Indonesia. \\ email:yuli_febri.anti16@yahoo.co.id
}

\begin{abstract}
The purpose of this study is to determine the ecological factor in the growth site of the Solanaceae family and the plant species of the Solanaceae family that can and can not be consumed in Tugumulyo District.The type of this research is descriptive exploration. Technique of taking data with observation and interview. The work done is direct observation to the field. Data obtained from the research are analyzed descriptively qualitative. The result of this research is ecological factor at the growth site of Solanaceae family in Tugumulyo District ranges between temperature $29^{\circ} \mathrm{C}-31^{\circ} \mathrm{C}$, humidity is $78 \%-86 \%$, and acidity degree $(\mathrm{pH})$ of the soil is 6,2-6,8. A total of 9 species that can be consumed and made into spices and vegetables are Capsicum annum, Capsicum, frutescens, Physalis angulata, Solanum indicum, Solanum lycopersicum, Solanum melongena, Solanum nigrum, Solanum torvum, Solanum tuberosum. And 2 species that can not be consumed by the public and toxic are Cestrum nocturnum and Datura metel which is an ornamental plant.
\end{abstract}

Keywords: Ecological Factor; Utilization; Solanaceae.

\section{PENDAHULUAN}

Solanaceae (suku terung-terungan) merupakan salah satu suku tumbuhan berbunga, herba atau perdu, dan kadang-kadang pohon. Suku Solanaceae terbagi kurang lebih 80 genus dan seluruhnya mencakup sekitar 1.700 jenis, yang tersebar di daerah- 
daerah iklim panas sampai daerah-daerah iklim sedang. Semua anggota famili Soalanaceae memiliki trikoma pada daun kelopaknya dan variasi bentuk trikomanya yaitu bentuk gelembung, sabit, bintang dan bejumbai (Tjitrosoepomo, 2007). Famili Solanaceae adalah salah satu famili terpenting dalam hal memenuhi kebutuhan manusia. Famili ini tidak hanya terdiri dari sayur-sayuran yang penting dan buah-buahan seperti kentang, tomat, terung, paprika, cabai, paprika hijau dan merah, tetapi juga digunakan sebagai tanaman hias contohnya petunia, dan juga untuk pengobatan, narkotika, obat bius dan bahkan beracun (Setshogo, 2015). Ada 8 genus dari famili Solanaceae yang berbentuk pohon yaitu Solanum, Lycianthes, Cestrum, Nolana, Physalis, Lycium, Nicotiana, dan Brunfelsia memiliki lebih dari 60\% spesies (Yadav et al., 2016).

Kecamatan Tugumulyo sebagai kawasan andalan dari Kabupaten Musi Rawas (Pemkab Mura, 2010) memiliki iklim tropis basah, suhu minimum $19.6^{\circ} \mathrm{C}$, pH tanah antara 4.5-6.0, dan curah hujan 2.285 per tahun yang menjadikan kawasan ini memiliki sektor unggulan, meliputi: peternakan, perikanan, dan pertanian (padi). Hal ini sesuai dengan pendapat Sunarjono (2007) bahwa tumbuhan solanaceae secara umum memerlukan tanah yang gembur, sedikit menggandung pasir, $\mathrm{pH}$ tanahnya 5-6, ditanam di dataran rendah sampai dataran tinggi dengan suhu udara sekitar $20^{\circ} \mathrm{C}$ serta memerlukan tanah yang beriklim basah (curah hujan 1000-2000 mm per tahun).

Berdasarkan observasi awal pada tanggal 5-6 Oktober 2016, banyak ditemukan berbagai jenis tumbuhan famili Solanaceae, namun hanya beberapa yang dikenal baik dan dikonsumsi oleh masyarakat. Selain itu tumbuhan dari famili Solanaceae yang lainnya belum mendapatkan perhatian dari masyarakat untuk dikembangkan atau dibudidayakan padahal mempunyai nilai ekonomis tinggi. Penelitian tentang faktor ekologi tumbuhan famili solanaceae juga belum pernah dilakukan sehingga belum ada data tentang suhu, kelembaban dan derajat keasaman sebagai faktor ekologi di lokasi tumbuhnya famili solanaceae serta pemanfaatannya di Kecamatan Tugumulyo. 
Berdasarkan latar belakang di atas, maka diperlukan penelitian untuk mengetahui faktor ekologi dan pemanfaatan tumbuhan famili Solanaceae di Kecamatan Tugumulyo.

\section{METODE PENELITIAN}

\section{a. Jenis Penelitian}

Jenis penelitian yang digunakan yaitu deskriptif eksploratif. Eksploratif dilakukan dengan cara jelajah bebas di sepuluh Desa di Kecamatan Tugumulyo. Tujuan dari jelajah bebas yaitu untuk menggambarkan sesuatu yang dilakukan dengan studi langsung ke lapangan mengenai objek yang diteliti supaya memperoleh pengetahuan yang lebih banyak tentang suatu keadaan.

\section{b. Waktu dan Tempat Penelitian}

Penelitian ini dimulai dari bulan Januari sampai bulan Maret 2017. Tempat penelitian yang terdiri dari sepuluh Desa yaitu Desa Dwijaya, Desa Mataram, Desa Sidoharjo, Desa Srikaton, Desa Tambahasri, Desa Tegal Rejo, Desa Trikoyo, Desa Widodo, Desa Wonorejo, dan Desa Wukirsari Kecamatan Tugumulyo.

\section{c. Bahan dan Alat}

Alat yang digunakan adalah kamera photo, termometer, termohigrometer, soiltester.

\section{d. Cara Kerja}

Oservasi lapangan yang dilakukan dengan cara menjelajahi lokasi penelitian kemudian melakukan pengukuran faktor ekologi yang meliputi pengukuran suhu, kelembaban, derajat keasaman $(\mathrm{pH})$ tanah. Serta melakukan wawancara terhadap masyarakat (informan) setempat tentang pemanfaatan tumbuhan famili Solanaceae yang terdapat di Kecamatan Tugumulyo Kabupaten Musi Rawas.

\section{e. Teknik Pengumpulan Data}

Teknik Pengumpulan data dalam penelitian ini melalui tahap-tahap yaitu teknik observasi mengenai faktor ekologi yang meliputi suhu, kelembaban, dan derajat keasaman $(\mathrm{pH})$ tanah yang terdapat di sepuluh Desa di Kecamatan Tugumulyo. Serta Teknik wawancara dilakukan dengan 
teknik wawancara semi struktural dengan mengajukan pertanyaan yang telah disiapkan. Menurut Yusuf (2014:377). mengemukakan bahwa teknik wawancara semi struktural dilakukan dengan menyusun rencana yang mantap terlebih dahulu, tetapi tidak menggunakan format dan urutan yang baku. Wawancara dilakukan untuk mengetahui data lisan dari masyarakat (informan) tentang pemanfaatan tumbuhan famili Solanaceae yang digunakan masyarakat sebagai tanaman pangan, tumbuhan obat, dan tanaman hias. Masyarakat yang diwawancarai dipilih menjadi informan umum dengan teknik snowball sampling. Menurut Sugiyono (2012:219) menyatakan bahwa teknik snowball sampling adalah teknik pengambilan sampel sumber data yang pada awal jumlahnya sedikit, lama-lama menjadi besar. Hal ini dilakukan karena dari jumlah sumber data yang sedikit itu tersebut belum mampu memberikan data yang memuaskan.

\section{f. Anaslis Data}

Semua data dianalisis secara deskriptif kualitatif dari hasil wawancara kepada masyarakat (informan) dengan mencocokkan manfaat tumbuhan famili solanaceae berdasarkan buku/jurnal/artikel. Serta hasil observasi lapangan yaitu pengukuran suhu, kelembaban dan derajat keasaman $(\mathrm{pH})$ tanah di lokasi tumbuhnya famili solanaceae dari sepuluh Desa di Kecamatan Tugumulyo Kabupaten Musi Rawas.

\section{HASIL DAN PEMBAHASAN}

Hasil pengukuran faktor ekologi yang dilakukan pada tanggal 14-19 Maret 2017 pada pukul 08.00 pagi-17.30 sore seperti yang terlihat pada Tabel 1 . 
Tabel 1.

Data faktor ekologi di lokasi tumbuhnya famili Solanaceae

\begin{tabular}{clccc}
\hline No. & \multicolumn{1}{c}{ Tempat } & $\begin{array}{c}\text { Rata-rata } \\
\text { Suhu (oC) }\end{array}$ & $\begin{array}{c}\text { Rata-rata } \\
\text { Kelembaban } \\
\mathbf{( \% )}\end{array}$ & $\begin{array}{c}\text { Derajat } \\
\text { Keasaman } \\
\text { tanah (pH) }\end{array}$ \\
\hline 1. & Desa Dwijaya & 29 & 79 & 6,8 \\
2. & Desa Mataram & 31 & 78 & 6,4 \\
3. & Desa Sidoharjo & 29 & 84 & 6,4 \\
4. & Desa Srikaton & 29 & 86 & 6,4 \\
5. & Desa & 29 & 80 & 6,6 \\
& Tambahasri & & & \\
6. & Desa Tegal & 29 & 84 & 6,6 \\
& Rejo & & & 6,6 \\
7. & Desa Trikoyo & 29 & 82 & 6,2 \\
8. & Desa Widodo & 29 & 82 & 6,4 \\
9. & Desa Wonorejo & 30 & 79 & 6,4 \\
10. & Desa Wukirsari & 31 & 78 & \\
\hline
\end{tabular}

Secara umum, hasil pengukuran faktor ekologi di sepuluh desa yang dijadikan lokasi penelitian mempunyai rata-rata suhu yaitu $29{ }^{\circ} \mathrm{C}-31^{\circ} \mathrm{C}$, kelembaban adalah 78\%-86\%, dan derajat keasaman $(\mathrm{pH})$ tanah adalah 6,2-6,8 yang hampir sama dan masing- masing desa meliputi perkebunan, hutan, sawah, tegalan, daerah pingiran sungai dan daerah pinggiran jalan, yang pada umumnya tempat tumbuh solanaceae. Dengan demikian, karena suhu, kelembaban, dan derajat keasaman $(\mathrm{pH})$ tanah hampir sama. Jadi, species yang ditemukan pada kesepuluh desa hampir sama. Menurut Sunarjono (2007), Suhu udara yang terlalu tinggi dapat menimbulkan kematian pada tanaman, dan sebaliknya suhu yang terlalu rendah juga menimbulkan kerusakan pada tanaman. Kelembaban udara yang terlalu rendah berpengaruh terhadap proses penyerapan unsur hara, terutama nitrogen dan fosfor dan kelembaban udara yang tinggi, pemanfaatan unsur hara dalam tanah tidak seimbang.

Derajat Keasamaan $(\mathrm{pH})$ tanah, berpengaruh langsung terhadap pertumbuhan tanaman, derajat keasaman tanah juga berpengaruh terhadap kehidupan organisme tanah sehingga mempengaruhi kesuburan tanah dan ketersediaan unsur hara tertentu. $\mathrm{pH}$ tanah yang terlalu rendah atau terlalu tinggi akan menyebabkan produksi buah rendah. Hal ini sesuai dengan hasil penelitian Parman (2007), bahwa suhu yang diukur pada saat 
penelitian berkisar antara $25,3^{\circ} \mathrm{C}-27,6^{\circ} \mathrm{C}$ dengan rata-rata $25,3^{\circ} \mathrm{C}$ dan kelembabab udara erkisar antara 79,7\%-85,0\% dengan ratarata $82,4 \%$. Sedangkan $\mathrm{pH}$ tanah yang diukur pada awal penelitian 5,4 dan yang diukur pada akhir penelitian adalah 5,6. Sehingga kisaran suhu, kelembaban udara, dan derajat keasaman $(\mathrm{pH})$ tanah tersebut sesuai dengan lingkungan untuk pertumbuhan spesies dari famili solanaceae. Selanjutnya, menurut Kotak et al. (2007), suatu organisme dikatakan mengalami stress atau cekaman panas atau suhu tinggi apabila pada lingkungan tumbuhnya organisme tersebut terpapar pada suhu yang melebihi suhu optimum yang diperlukan.

Berdasarkan hasil wawancara kepada masyarakat (informan) diperoleh 11 spesies tumbuhan famili Solanaceae di Kecamatan Tugumulyo Kabupaten Musi rawas. Sebanyak 9 spesies yang dapat dikonsumsi dan dijadikan bumbu masakan dan sayur adalah Capsicum annum, Capsicum, frutescens, Physalis angulata, Solanum indicum, Solanum lycopersicum, Solanum melongena, Solanum nigrum, Solanum torvum, Solanum tuberosum. Dan 2 spesies yang tidak dapat dikonsumsi oleh masyarakat dan beracun adalah Cestrum nocturnum dan Datura metel yang merupakan tanaman hias.

Dilihat dari segi pemanfaatan tumbuhan famili Solanaceae memiliki banyak manfaat diantaranya sebagai tanaman obatobatan, sayur dan bumbu masakan. Seperti genus Physalis, species yang ditemukan Physalis angulata. Daun Ceplukan (Physalis angulata) bermanfaat sebagai obat Batuk, flu, sakit gondong, kencing manis, epilepsi, pembengkakan prostat (Faiha, 2015). Korengan, cacar, hipertiroid, diabetes, darah tinggi, panas dalam (Permadi, 2009). Sedangkan buah ciplukan sendiri sering dimakan langsung untuk mengobati epilepsi, sulit buang air kecil, dan penyakit kuning. Capsicum annum buahnya dapat digolongkan sebagai sayuran maupun bumbu, tergantung bagaimana digunakan. Sebagai bumbu, buah cabai yang pedas sangat populer di Asia Tenggara sebagai penguat rasa makanan. Selain itu Capsicum annum digunakan sebagai bumbu masak, sariawan, flu, antioksidan, antifungi, antibakteri, penurun kadar gula darah, dan penambah napsu makan. Hal ini sesuai dengan hasil penelitian De Lucca et al. (2006) dan Soumya and Bindu (2012), yaitu Capsicum 
annum sebagai antifungi. Selanjutnya Tundis et al. (2011), sebagai penurunan kadar gula darah. Selanjutnya Santos et al. (2007), dapat menghambat pertumbuhan bakteri Streptococcus mutans dan antioksidan (Lei Chen et al., 2012). Selanjutnya Capsicum frutescens, buahnya digunakan sebagai sayuran, bumbu masak, acar, dan asinan. Daun muda dapat dikukus untuk lalap. Capsicum frutescens dapat diperbanyak dengan biji. Selain itu Capsicum frutescens dapat mengobati luka dan rematik (Sumpena, 2013).

Beberapa species dari famili Solanaceae digolongkan kedalam tanaman beracun seperti Datura metel. Datura metel digolongkan kedalam tanaman beracun karena tumbuhan ini mengandung racun. Kandungan racunnya adalah berupa zat alkaloid yang mempunyai efek halusinogen terutama pada bagian bijinya (Yadav et al., 2016).

\section{UCAPAN TERIMA KASIH}

Terima kasih terhadap pihak STKIP-PGRI Lubuklinggau yang telah memberikan bantuan dana penelitian, sehingga penelitian ini dapat terlaksana dengan baik dan lancar.

\section{KESIMPULAN}

Faktor ekologi di lokasi tumbuhnya family Solanaceae di Kecamatan Tugumulyo berkisar diantara suhu yaitu $29^{\circ} \mathrm{C}-31^{\circ} \mathrm{C}$, kelembaban adalah 78\%-86\%, dan derajat keasaman $(\mathrm{pH})$ tanah adalah 6,2-6,8.

Sebanyak 9 spesies yang dapat dikonsumsi dan dijadikan bumbu masakan dan sayur adalah Capsicum annum, Capsicum, frutescens, Physalis angulata, Solanum indicum, Solanum lycopersicum, Solanum melongena, Solanum nigrum, Solanum torvum, Solanum tuberosum. Dan 2 spesies yang tidak dapat dikonsumsi oleh masyarakat dan beracun adalah Cestrum nocturnum dan Datura metel yang merupakan tanaman hias. 


\section{DAFTAR PUSTAKA}

De Lucca, A.J., Boue, S., Palmgren, M.S., Maskos, K., and Cleveland, T.E. (2006). Fungicidal properties of two saponins from Capsicum frutescens anda the relationship of structure and fungicidal activity. Canadian Journal of Microbiology, 52(4), 36-42.

Faiha, A. (2015). Apotek Hidup. Jakarta: Genis Publisher.

Kotak, S., Larkindale, J., Lee, U., Von Koskull-Doring, P., Vierling, E., Scharf, K.D. (2007). Complexity of the heat stress response in plants. Current Opinion in Plant Biology, 10(3), 310-316.

Lei Chen., Ji-Eun Hwang., Kang Mo Gu., Jung-Hyun Kim., Boram Choi., Kyung-Sik Song., Youmie Park., YoungHwa Kang. (2012). Comparative study of antioxidant effects of fivr Korean Varieties res pepper (Capsicum annuum L) extract from various parts including placenta, stalk, and pericarp. Food Science and Biotechnology, 21(3), 715-721.

Pemerintah Kabupaten Musi Rawas (Pemkab Mura). (2010). Rencana Pembangunan Jangka Panjang Kabupaten Musi Rawas Tahun 2005-2025. (Online), (http://bappeda. musirawaskab.go.id), diakses 07 Desember 2016.

Parman, S. (2007). Pengaruh Pemberian Pupuk Organik Cair terhadap Pertumbuhan dan Produksi Kentang (Solanum tuberosum L.). Buletin Anatomi dan Fisiologi, 15(2), 1-11.

Permadi, A. (2006). Tanaman Obat Pelancar Air Seni. Jakarta. Penebar Swadaya.

Santos, M. M., Vieira-da-Motta, O., Vieira, I.J., Braz-Filho, R., Gonçalves, P.S., Maria, E.J., Terra, W.S., Rodrigues, R., Souza, C.L. (2007). Antibacterial activity of Capsicum annum extract and synthetic capsaisinoids derivates against S treptococcus mutans. J Nat Mes, 66(2), 354-356. 
Setshogo, M.P. (2015). A Review of Some Medicinal and or Hallucinogenic Solanaceous Plants of Botswana: The Genus Datura L. International Journal of Medicinal Plants and Natural Products (IJMPNP), 1(2), 15-23.

Soumya, S.L and Bindu, R Nair. (2012). Antifungal efficacy of Capsicum frutescens L. extract against some prevalent fungal strain associates with graoundnut storeage. Journal of Agricultural Technology, 8(2), 739-750.

Sugiyono. (2012). Metode Penelitian Kuantitatif, Kualitatif, dan $R \& D$. (pp. 219). Bandung: Alfabeta.

Sumpena, U. (2013). Penetapan kadar Capsaicin Beberapa Jenis Cabe (Capsicum sp) di Indonesia. Jurnal Ilmu Pertanian, 9(2), 9-16.

Sunarjono, H. (2007). Bertanam 30 Jenis Sayur. Jakarta: Penebar Swadaya.

Tjitrosoepomo, G. (2007). Taksonomi tumbuhan (Spermatophyta). (pp. 353). Yogyakarta: Gadjah Mada University Press.

Tundis, R., Loizzo, M.R., Menichini, F., Bonesi, M., Conforti, F., Statti, G., De Luca, D., De Cindio, B., Menichini, F. (2011). Comparative study on the chemical composition, antioxidant properties and hypoglycaemic activities of two Capsicum annum I. cultivars (Acuminatum small and Cerasiferum). J Plant Foods for Human Nutrition, 66(3), 261 $-269$.

Yadav, R., Rathi, M., Pednekar, A., and Rewachandani, Y. (2016). A Detailed Review on Solanaceae Family. European Journal of Pharmaceutical and Medical Research, 3(1), 369-378. 
Febrianti, Y dan Krisnawati, Y

Yusuf, M. (2014). Metode Penelitian Kuantitatif, Kualitatif \& Penelitian Gabungan. (pp. 377). Jakarta: Kencana Praneda Media Group. 